\title{
Estudo da evasão estudantil no curso de Licenciatura em Química do IFMA - campus São Luís Monte Castelo
}

\author{
Study of dropout in undergraduate degree in chemistry teaching at IFMA - São Luís Monte \\ Castelo campus \\ Estudio de la deserción estudantil en el curso de pregrado para la formación de professores de \\ química en IFMA - campus São Luís Monte Castelo
}

Recebido: 11/01/2022 | Revisado: 15/01/2022 | Aceito: 16/01/2022 | Publicado: 18/01/2022

Rogério de Mesquita Teles
ORCID: https://orcid.org/0000-0001-9789-1847
E-mail: rogerioteles@ifma.edu.br
Illana Karina Dias Ribeiro
Instituto Federal de Educação Ciências e Tecnologia do Maranhão, Brasil
ORCID: https://orcid.org/0000-0003-3788-106X
E-mail: illanakarina96@outlook.com
Regina Lucia Muniz Ribeiro
Instituto Federal de Educação Ciências e Tecnologia do Maranhão, Brasil
ORCID: https://orcid.org/0000-0003-1910-6182
Instituto Federal de Educação Ciências e Tecnologia do Maranhão, Brasil
E-mail: reginamuniz@ifma.edu.br
Lara Rubia Silva Teles
ORCID: https://orcid.org/0000-0001-7112-5781
Instituto Federal de Educação Ciências e Tecnologia do Maranhão, Brasil
E-mail: lara.teles@ifma.edu.br

\section{Resumo}

A evasão estudantil tem sido motivo de preocupação das instituições de ensino superior no Brasil e no mundo. Objetivando compreender a evasão estudantil no curso de Química Licenciatura do IFMA-Monte Castelo, analisou-se as turmas de 2002 a 2018. Utilizou-se metodologia descritiva e analítica, abordando quanti e qualitativamente dados obtidos do sistema acadêmico e questionários aplicados. Para as turmas de 2002 a 1013 , a de 2003 teve a maior quantidade de formados (74\%) e menos evadidos (26\%). A maior evasão ocorreu na turma de $2006(84 \%)$ e a turma de 2010 foi a que menos formou (9\%). Para as turmas de 2014 a 2018, a de 2014 apresentou maior evasão (77\%) e a de 2018, a menor (7\%). Dificuldades financeiras, mudança de município/distância, filhos e emprego levaram à evasão estudantil. Para prevenir e combater a evasão, a instituição deveria acompanhar e orientar os estudantes, assim como aumentar o número de bolsas.

Palavras-chave: Educação superior; Ensino; Evasão escolar; Formação de professores.

\begin{abstract}
Student dropout has been a concern for higher education institutions in Brazil and worldwide. Aiming to understand the student dropout in the Undergraduate Chemistry course of IFMA-Monte Castelo, we analyzed the classes from 2002 to 2018. A descriptive and analytical methodology was used, addressing quanti and qualitatively data obtained from the academic system and questionnaires applied. For the classes of 2002 to 2018 , the class of 2003 had the highest number of graduates (74\%) and the lowest number of dropouts (26\%). The highest evasion occurred in the class of $2006(84 \%)$ and the class of 2010 had the lowest number of graduates (9\%). For the classes of 2014 to 2018, the 2014 class had the highest evasion (77\%) and the 2018 class had the lowest (7\%). Financial hardship, moving to a different county/distance, children, and employment led to student dropout. To prevent and combat dropout, the institution should monitor and guide students, as well as increase the number of scholarships.
\end{abstract}

Keywords: Higher education; School dropout; Teaching; Teacher education.

\section{Resumen}

La deserción estudiantil ha sido motivo de preocupación en las instituciones de educación superior de Brasil y del mundo. Con el objetivo de entender el abandono de los estudiantes en el curso de Pregrado de Química del IFMAMonte Castelo, analizamos las clases desde 2002 hasta 2018. Se utilizó metodología descriptiva y analítica, abordando cuantitativa y cualitativamente los datos obtenidos del sistema académico y los cuestionarios aplicados. Para las clases de 2002 a 1013, la clase de 2003 fue la que tuvo el mayor número de estudiantes graduados (74\%) y la que menos 
abandonó (26\%). La evasión más alta se produjo en la clase de 2006 (84\%) y la clase de 2010 tuvo el menor número de graduados (9\%). Para las clases de 2014 a 2018, la clase de 2014 mostró la mayor evasión (77\%) y la clase de 2018 la menor (7\%). Las dificultades económicas, el cambio de municipio/distancia, los hijos y el empleo provocaron el abandono de los estudiantes. Para prevenir y combatir la evasión, la institución debe controlar y orientar a los estudiantes, así como aumentar el número de becas.

Palabras clave: Educación superior; Abandono escolar; Enseñando; Formación de profesores.

\section{Introdução}

\subsection{Caracterizando o IFMA}

Com o declínio da economia do cultivo do café no início do século XX e o crescimento do capital industrial, surge a demanda por mão de obra qualificada. Mesmo com o advento da chegada de imigrantes europeus ao Brasil, essa demanda não é plenamente atendida. Nesse contexto, mediante a exigência do setor industrial, foi editado em 23 de fevereiro de 1909 , pelo então presidente da república Nilo Peçanha, o decreto 7.566, o qual criou as Escolas de Aprendizes e Artífices - marco inicial da Educação Profissional no país. Em cada uma das 19 capitais brasileiras da época foi criada uma dessas escolas, dentre as quais a Escola dos Artífices do Maranhão (Colombo, 2020).

O próprio decreto (Brasil, 1909), em seus “considerandos”, se justifica quando se propõe a proporcionar "aos filhos dos desfavorecidos da fortuna o preparo técnico e intelectual, além de afastá-los da ociosidade, do vício e do crime”. Para instalação dessas escolas, o governo federal bancava o quadro de pessoal e material de consumo, enquanto os governos estaduais se responsabilizavam com os prédios, que, de acordo com Lima (2014), em geral não eram apropriado para essa modalidade de ensino. Em função dessas condições, prédios impróprios, oficinas precárias e quantidade insuficiente de professores qualificados, essas escolas registravam altos índices de evasão estudantil (Santos Junior, 2017).

Mesmo diante dessa realidade, a educação profissional foi se consolidando ao longo do tempo e, com a promulgação da Constituição de 1937, as Escolas de Aprendizes e Artífices são transformadas em Liceus Industriais, com o propósito de ofertar ensino profissional a todos os ramos e graus, como forma de dar suporte à industrialização com a formação operários. Com isso, a Escola dos Artífices do Maranhão a qual foi transformada em Liceu Industrial de São Luís.

Esses Liceus Industriais foram transformados em Escolas Industriais e Técnicas pelo Decreto no 4.127, de 1942. Nesse mesmo ano foi sancionada a Lei Orgânica do Ensino Industrial, no bojo da Reforma Capanema, dando continuidade à destinação do ensino profissional aos menos favorecidos, sempre excluídos das políticas públicas. No tocante à política educacional, efetivava-se o ensino secundário como preparatório e propedêutico à educação superior, apartado dos cursos profissionalizantes (Lima, 2014; Manfredi, 2002).

Nesse contexto, o Liceu Industrial de São Luís também foi transformado em Escola Industrial e Técnica de São Luís, a qual sofre nova alteração, em 1959, quando foi transformada em Escola Técnica Federal do Maranhão, por determinação da Lei $n^{\circ}$ 3.552, que transformou as Escolas Industriais e Técnicas em autarquias, ganhando a denominação de "Escolas Técnicas Federais", além de autonomia didática e de gestão.

Em 1989, a Escola Técnica Federal do Maranhão foi transformada em Centro Federal de Educação Tecnológica do Maranhão - CEFET-MA, tendo suas atribuições ampliadas para graduação e pós-graduação. Com a sanção da Lei 11.892 , em 29 de dezembro de 2008, passou a ser o Instituto Federal de Educação, Ciência e Tecnologia do Maranhão - IFMA. A partir daí, o IFMA passa por ampla expansão, chegando a 30 campi em todo o estado do Maranhão, sendo o Campus São Luís - Monte Castelo o mais antigo e o maior deles (Teles, 2014).

Desde 1997, os Cefets já gozavam de autonomia para criar vagas em cursos da educação básica, técnica e tecnológica da educação profissional. Entretanto, a autonomia para criar cursos de formação inicial de professores só se deu no ano de 2000 , 
com a edição do Decreto 3.462 (Brasil, 2000). No Cefet-MA, a oferta da primeira turma de Licenciatura em Química ocorreu no segundo semestre de 2002 .

\subsection{Definindo Evasão Estudantil}

No Brasil, o fenômeno da evasão na educação superior brasileira ganha proporção a partir de 1995, ano em que a Secretaria de Educação Superior do Ministério da Educação organiza o Seminário sobre evasão nas universidades brasileiras, onde se institui a Comissão Especial de Estudos sobre a Evasão nas Universidades Públicas Brasileiras.

Dois anos depois, a Comissão apresenta seu relatório, no qual sugere a compreensão da evasão do ensino superior em três níveis: curso, instituição e sistema. A evasão de curso, quando o estudante desliga-se do curso superior em situações diversas tais como: abandono (deixa de matricular-se), desistência (oficial), transferência ou reopção (mudança de curso), exclusão por norma institucional; evasão da instituição, quando o estudante desliga-se da instituição na qual está matriculado; e evasão do sistema de ensino superior, quando o estudante abandona de forma definitiva ou temporária o ensino superior (MEC, 1997). Segundo esse documento, o conceito de evasão dos cursos de graduação, considerado para aquele estudo foi considerado "como a saída definitiva do aluno de seu curso de origem, sem concluí-lo” (Andifes, A., Abruem, A., \& SESu/MEC, 1996, p.56).

Verifica-se na literatura o uso do termo evasão sendo empregado com largo espectro de entendimentos. Costa (1991), define como sendo a saída do estudante da universidade ou de um de seus cursos, de maneira definitiva ou temporária, por qualquer motivo (financeiro, econômico ou social), exceto a diplomação. Para Baggi e Lopes (2011) a evasão é "saída do aluno da instituição antes da conclusão do seu curso", enquanto para Castro e Teixeira (2014) seria o "desligamento do curso superior por qualquer outro motivo que não a diplomação".

Na mesma linha, Fritsch (2015) afirma que "a evasão escolar significa desistência dos estudos por qualquer motivo, exceto sua conclusão" e Biazus (2004) que evasão é "saída do aluno da universidade, ou seja, de um de seus cursos, definitiva ou temporariamente, por qualquer motivo, exceto a diplomação”. Já Abbad, Carvalho e Zerbini (2006) definem o processo como a "desistência definitiva do aluno em qualquer etapa do curso".

De qualquer forma, como afirmam Fritsch, Rocha e Vitelli (2015) sabe-se que a evasão estudantil é um processo de exclusão determinado por fatores e variáveis internas e externas às instituições de ensino. Trata-se, portanto, de um fenômeno complexo, multifacetado e multicausal, intrinsecamente ligado com fatores pessoais, sociais e institucionais, que podem resultar na saída provisória do aluno da escola ou na sua saída definitiva do sistema de ensino, como concluem Dore, Sales e Castro (2014).

Complementarmente, Vitelli e Fritsch (2016), inserem na discussão sobre evasão estudantil duas dimensões, a temporalidade e a granularidade, sendo que a primeira se refere à análise do fenômeno (curso, instituição ou sistema) ao passo que a última pode ser imediata, por período definido ou, até mesmo, definitiva.

No modelo proposto por Tinto (1975) são observados dois processos fundamentais para a tomada de decisão do estudante pela permanência ou evasão do mesmo na instituição: a integração acadêmica e a integração social. Nesse modelo, a integração acadêmica diz respeito ao sentimento de o estudante estar integrado ao ambiente da instituição (desempenho acadêmico, autoestima, desenvolvimento pessoal), assim como ao sentimento de gostar dos conteúdos do curso se identificar com suas normas e valores e com o papel de estudante. Já a integração social diz respeito ao sentimento de pertencer a um grupo e de sentir-se bem no ambiente da universidade (contatos com colegas de curso, participação em atividades sociais na universidade), assim como contatos informais com professores e com a equipe de apoio dos cursos (gestores, coordenadores e funcionários da instituição) (Tinto, 1975, 1993, 1997).

No que diz respeito aos documentos atuais do MEC para a conceituação de evasão escolar, observa-se que o Guia de Referência Metodológica da Plataforma Nilo Peçanha (PNP) - ambiente virtual de coleta, validação e disseminação das 
estatísticas oficiais da Rede Feral na qual se inclui o IFMA -, classifica a situação do aluno em três situações - como mostrado no Quadro 1 -, “considerando o conjunto de alunos ingressantes no início de um determinado ciclo quando do momento de análise, cada estudante poderá se encontrar em apenas uma das 03 situações de matrícula (Moraes, G. H. et al., 2018, p. 19):

Quadro 1. Situação de matrícula.

\begin{tabular}{|c|c|}
\hline Evadido & Aluno que perdeu o vínculo com a Instituição antes da conclusão do curso \\
\hline Retido & Aluno que permaneceu matriculado por período superior ao tempo previsto para a integralização do curso \\
\hline \multirow[t]{3}{*}{ Concluinte } & Aluno Formado ou Integralizado em fase escolar, sendo: \\
\hline & $\begin{array}{l}\text { Formados: Alunos que concluíram com êxito todos os componentes curriculares do curso, fazendo jus à } \\
\text { certificação; }\end{array}$ \\
\hline & $\begin{array}{l}\text { Integralizados em fase escolar: Alunos que concluíram a carga horária das unidades curriculares de um } \\
\text { curso, mas ainda não podem receber a certificação por não terem concluído componentes curriculares como } \\
\text { Estágio, Extensão obrigatória, TCC, ENADE, etc. }\end{array}$ \\
\hline
\end{tabular}

Fonte: Moraes, G. H. et al. (2018).

Por outro lado, o próprio MEC, no documento Metodologia de Cálculo dos Indicadores de Fluxo da Educação Superior, Inep (2017), relata que, em função da forma como a educação superior se organiza (diversidade de currículos, formas de organização dos cursos e critérios diversificados de avaliação, progressão, aproveitamento de estudos e conclusão), fica inviável o cálculo de indicadores intermediários gerais de trajetória acadêmica do discente, ou seja "os conceitos terminativos de desistência (evasão) e conclusão permanecem válidos, mas os conceitos que representam a transição entre etapas da educação básica (promoção e repetência) não são adequados" (Inep, 2017, p. 11). O documento também define evasão como sendo "saída antecipada, antes da conclusão do ano, série ou ciclo, por desistência (independentemente do motivo)" (Inep, 2017, p. 11), exceto a interrupção do programa em decorrência de falecimento do discente.

\subsection{Evasão Estudantil da educação superior}

Ao analisar a literatura sobre evasão estudantil na educação superior, observa-se que são múltiplas as abordagens em instituições distintas, cursos e períodos, visão dos atores (estudantes, coordenadores, professores, gestores), assim como diversidade de amostragens e populações.

É comum esses trabalhos se classificarem em dois grandes grupos, os que abrangem motivações alegadas para a evasão (análises de dados oficiais, sem avaliar a decisão pessoal do estudante) e os abrangem a avaliação educacional e a identificação do perfil do estudante evadido (Silva, 2013).

Avaliando a evasão estudantil em cinco cursos de graduação da UFMG, Adachi (2009) observou que cursos com menores notas para o acesso (como Matemática, Química e História) apresentam maiores índices de evasão. O estudo conclui que infrequência, distanciamento da família (aqueles oriundos do interior), condição socioeconômica, trabalho e insatisfação com o curso foram os principais fatores causadores da evasão.

Analisando dados oficiais, de 2000 a 2005, acerca da evasão estudantil em instituições de educação superior brasileiras, Silva Filho et al. (2007) estimaram em 22\% a taxa de evasão. Essa taxa parece se estabilizar próximo aos 13\% a partir de 2010, como sugerido por Nunes (2013). 
Buscando identificar taxas de evasão de cinco países sul-americanos, usando 2000 como o ano-referência, Parrino (2009) chegou aos seguintes valores: 35\% para a Argentina, 30\% para o Chile, 25\% para o Paraguai, 22\% para o Uruguai e $14 \%$ para o Brasil.

Já os dados da OCDE (2010), usando o ano de 2006 como referência, registram números mais elevados que o Brasil, como Itália (58\%), Suécia (52\%), França (41\%) e os Estados Unidos (34\%).

No que diz respeito ao estudo da evasão em cursos de licenciatura no âmbito dos Institutos Federais, verifica-se na literatura uma quantidade ainda pouco expressiva, destacando-se os trabalhos de Almeida e Schimiguel (2011) e de Oliveira, Anjos e Rodrigues (2013) que apontam formação profissional ineficaz, baixos salários e condições inapropriadas de trabalho como causas da diminuição na procura por cursos de licenciatura e das altas taxas de evasão nos cursos de formação de professores dos IFs.

\section{Metodologia}

A pesquisas aborda método misto, pois se utiliza dos pontos fortes de cada uma de ambas abordagens, quantitativa e qualitativa, como aponta Lorenzini (2017).

Para a pesquisa quantitativa e qualitativa foi realizado levantamento no sistema acadêmico do Instituto Federal de Educação, Ciência e Tecnologia do Maranhão Campus São Luís - Monte Castelo com o objetivo de obter informações acerca do número de estudantes formados, evadidos, retidos e trancados desde o ano de 2002 até o ano de 2018. O período da pesquisa se deu até o ano de 2018.2.

No aspecto qualitativo foram aplicados questionários com estudantes evadidos - onde conseguimos 47 respostas -, como forma de verificar os principais aspectos que influenciam os estudantes a abandonarem o curso antes de seu término, seguido de uma análise literária a fim de compreender os fatores que favorecem a evasão estudantil. Nesse estudo, é importante ressaltar a dificuldade de contatar esses alunos evadidos por vários motivos, além da dificuldade de se obter respostas, por isso a amostra utilizada é satisfatória em relação a quantidade de alunos evadidos. Apesar de os dados obtidos mostrarem porcentagem, a leitura deles é voltada principalmente para os aspectos qualitativos, onde buscamos compreender os fatores que favorecem a evasão estudantil.

De posse dessas informações foram elaborados gráficos e planilhas no Excel para uma melhor discussão dos resultados obtidos e assim analisar o número de alunos, por turma, que abandonaram o curso e os que o concluíram, além de quantificar os aspectos que mais influenciaram os alunos a evadirem.

E, por fim, os dados coletados foram analisados através da frequência absoluta, frequência relativa, média aritmética e desvio padrão.

Para fins desta pesquisa, considera-se situações de matrícula apontadas pela Plataforma Nilo Peçanha (MORAES, G. H. et al., 2018, p. 19), com a adaptação que considera concluintes "integralizados em fase escolar" como retidos. Assim, é importante enfatizar que o estudo considerou evadido o aluno que perdeu o vínculo com a instituição, sem um retorno futuro; retido, o aluno que se encontra matriculado, porém passou do prazo para concluir o curso; e matriculado, o aluno está dentro do tempo hábil para concluir.

\section{Resultados e Discussão}

Para tornar mais coerente a discussão, os dados obtidos foram divididos em dois grupos: um com as turmas de 2002 a 2013, gráfico 1, e outro com as turmas de 2014 a 2018, Gráfico 2. 
Gráfico 1:Turmas de 2002 a 2013.

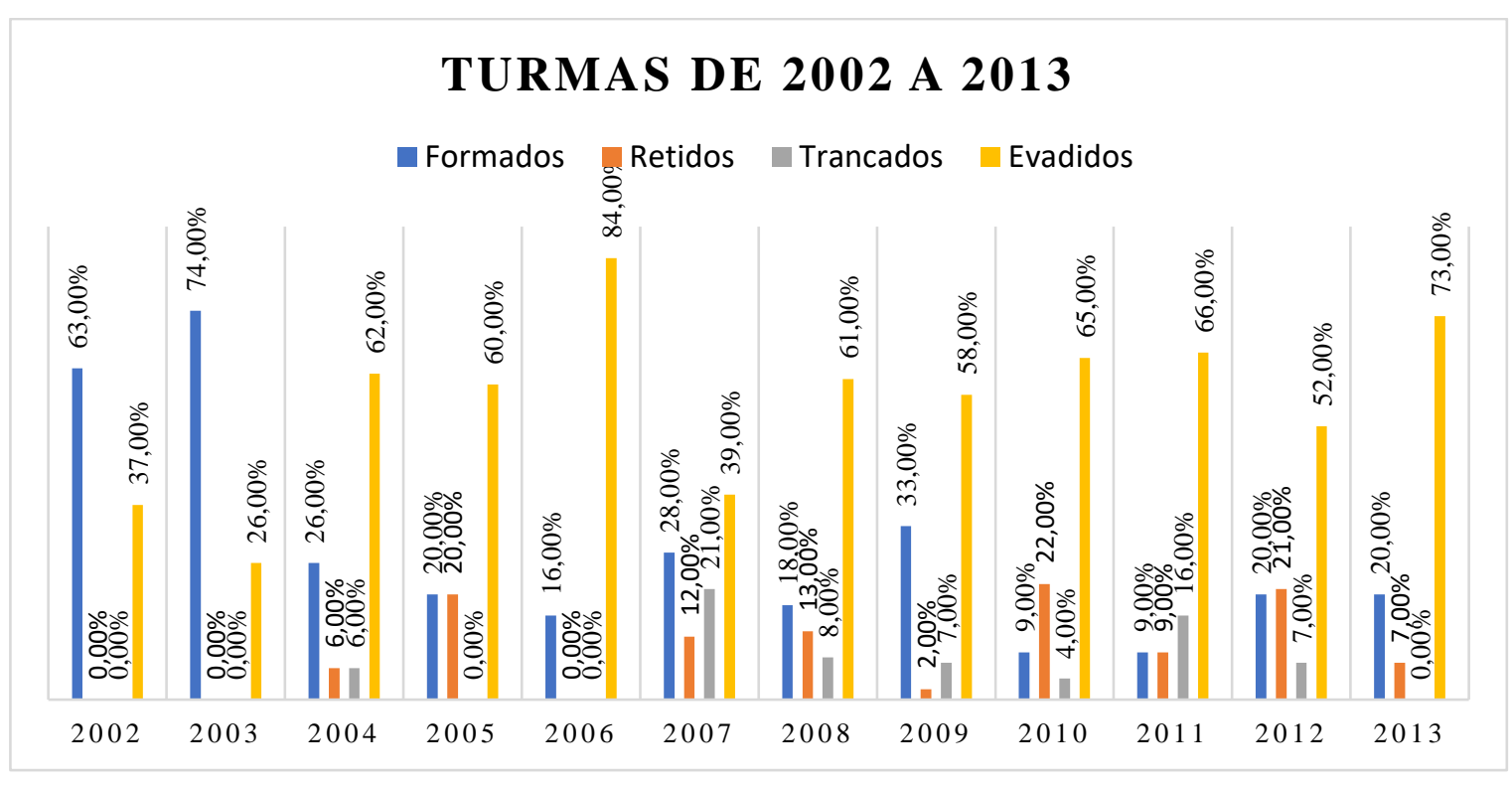

Fonte: Autores (2021).

É possível observar que na turma inicial houve um grande número de alunos formados, com $63 \%$ de formados, a turma teve um bom aproveitamento. Além de ser a turma com maior número de estudantes formados, essa também foi a turma com o menor número de evadidos no período, $26 \%$.

$\mathrm{Na}$ turma de 2004, apenas $26 \%$ da turma concluiu o curso, tendo a maioria dos estudantes evadido e alguns retidos. Desde o início do seu funcionamento, a evasão afeta os alunos do curso de licenciatura em química do campus São Luís - Monte Castelo do IFMA. O comportamento para a turma de 2005 é bem semelhante.

O maior número de evadidos se verifica na turma de 2006, com índice de evasão de $84 \%$. O restante da turma formouse. Observamos que houve uma progressão no número de evadidos em relação às turmas iniciais. Para a turma de 2007, o número de alunos evadidos se aproxima do número de formados, assim como observamos que mais de $40 \%$ dos estudantes da turma encontram-se retidos ou com matrícula trancada.

Nas turmas de 2008 a 2011, o perfil de evasão é bem semelhante e elevado, com destaque para as turmas de 2010 e 2011 que, além de alto índice de evasão foram as que menos formaram alunos - 9\% cada uma delas. As turmas de 2012 e 2013 formaram um quinto da turma, cada, mas com evasão também em patamares elevados, com destaque para esta última que ultrapassa $70 \%$ da turma. 
Gráfico 2: Turma de 2014 a 2018.

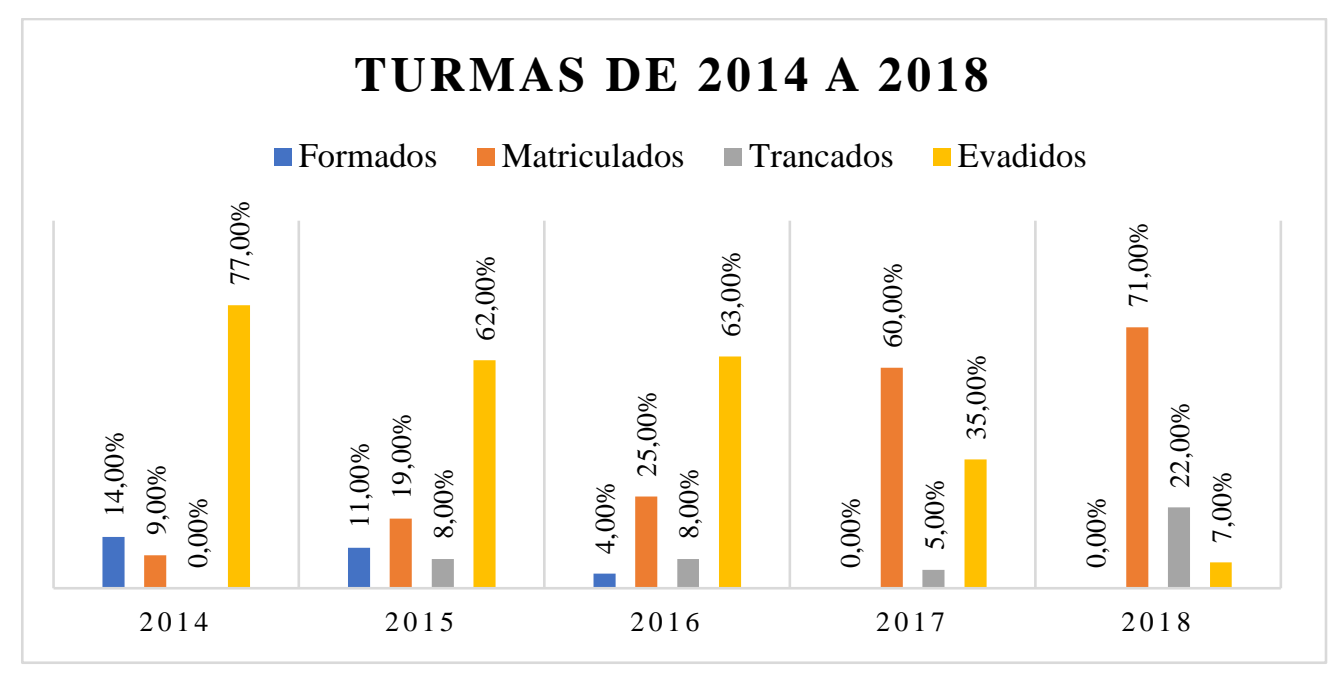

Fonte: Autores (2021).

A turma de 2014 apresentou índice de evasão muito elevado (77\%), que somados aos alunos com matrícula trancada, chega a quase $90 \%$ da turma. Apenas $14 \%$ da turma concluiu o curso.

O perfil do gráfico de evasão para as turmas de 2015 e 2016 é bem parecido, com mais de $60 \%$ da turma evadida e baixo número de estudantes formados.

As turmas de 2017 e 2018 ainda não haviam completado o tempo para terem estudantes formados no momento da coleta dos dados desta pesquisa, mas se percebe considerável evasão em ambas. Por outro lado, o número de estudantes matriculados é muito significante.

Pela análise das respostas ao questionário aplicado junto aos alunos evadidos, podemos perceber que há descontentamento de muitos alunos, pois o curso é organizado por semestre, mas só há uma entrada de estudantes por ano, o que faz com que não haja oferta de todas as disciplinas em todos os semestres. Caso o aluno reprove em uma ou mais disciplinas (ou não consiga cursá-las por qualquer motivo), ele só poderá refazê-las no ano seguinte, ocasionando assim um atraso de, no mínimo, um ano, pois as disciplinas dependem de pré-requisitos, provocando, por consequência, atraso no término do curso e desânimo em muitos estudantes, o que, muitas vezes, resulta em evasão estudantil.

Outra razão que tem contribuído para o aumento da evasão escolar, é o fato de o estudante já matriculado no curso de graduação, poder aderir a outro curso pelo Sistema de Seleção Unificada (Sisu), sem a necessidade de prestar outra prova do Exame Nacional do Ensino Médio (Enem), o que se constitui significativa diferença em relação ao vestibular tradicional. Conforme Ribeiro e Morais (2020, p. 14), uma opção de curso feita por um aluno, quando ele não possui ideia ou conhecimento de sua estrutura e seu funcionamento, pode abrigar fatores como status social, bom relacionamento com familiares e amigos, uma noção não muito integrada sobre a realidade do mercado de trabalho, as suas exigências e a obrigação social de ingresso em uma universidade.

Segundo Rangel et al. (2019, p. 30), existem indícios de fatores relacionados a vulnerabilidade dos alunos que favorecem um crescente aumento da evasão da rede de ensino superior e privada, esses indícios estão associados a políticas nacionais para o ensino superior, esse aumento pode ser justificado pela mobilidade acadêmica por meio de transferência ou abandono do curso, e uma possível reentrada na rede através do Enem, Sisu e Fieis.

Dessa forma, podemos perceber a influência do Enem/Sisu no aumento da frequência de evasão escolar, pois isso facilita a mobilidade do aluno com outros cursos, fazendo com que os alunos mudem de curso facilmente. Essa mobilidade pode 
favorecer a evasão. Podemos também levar consideração o fato de que os alunos ao se inscreverem em qualquer curso podem acabar tirando a vaga de outro aluno que de fato almeja aquele curso.

Quando indagados sobre o motivo de ter escolhido o IFMA, a maior frequência de respostas (49\%) apontou influência familiar, seguida de perspectiva de trabalho (19\%), vocação (17\%) e outros (15\%). Percebemos que já na entrada do aluno há uma fragilidade, o fato de o mesmo entrar sem vocação, aptidão ou mesmo sem conhecer o curso, o que pode afetar o desempenho do aluno, pois o mesmo pode não ter a determinação necessária para prosseguir e finalizar o curso. Nessa mesma direção, Santos (2005, p. 58) verificou que vários fatores influenciam na escolha de uma profissão, dentre eles a influência da família, logo esse fator pode ajudar ou dificultar na escolha, contudo é necessário que no momento da escolha o aluno leve em consideração o seu autoconhecimento juntamente com o conhecimento do projeto do país e o valor dado a profissão pela família.

Sem dúvidas, isso pode influenciar diretamente na identificação ou não do estudante com o curso, que no caso desta pesquisa, verificamos que $83 \%$ dos respondentes afirmaram não terem se identificado. Isso pode quebrar a necessária interação para permanência do aluno, "existe uma interação importante entre a qualidade da instituição, a composição de seus alunos e o desempenho individual e, portanto, persistência na faculdade.” (Tinto, 1975, p. 113).

No que diz respeito ao motivo que o levou a deixar o curso, a maior frequência (40\%) apontou para a dificuldade em conciliar o curso com as demais as atividades do estudante, seguida de fatores familiares (20\%), emprego/trabalho (19\%) e mudança de endereço.

$\mathrm{Na}$ verdade, esses fatores apontados em maior frequência estão muito intimamente relacionados. A dificuldade em conciliar os estudos com outras tarefas, certamente, predomina devido ao fato de o curso de Licenciatura em Química do IFMA campus São Luís - Monte Castelo ocorrer em horário integral, empecilho para alunos que trabalham ou que têm filhos, por exemplo. Se os horários do curso fossem organizados em um único turno talvez resolvesse essa questão da conciliação. Isso mostra que, conforme aponta Tinto (1975, p. 103), “a persistência na faculdade, no entanto, não é simplesmente o resultado de características individuais, experiências anteriores ou compromissos anteriores”. Somando-se a isso, há outras condições que vão além do próprio aluno, como problemas de infraestrutura da cidade e pouca ação de políticas assistenciais estudantis, já que a necessidade de se locomover e prover seu sustento não pode ser ignorada.

Sobre o desejo de mudança no curso, as respostas apontaram maior frequência para didática do professor (51\%), seguida de aulas de laboratório (23\%), ementa/horário (13\%) e prédio (9\%). Por isso é necessário levar em consideração também a interação do aluno com a instituição e o corpo docente, pois a persistência do aluno para concluir seu curso está associado ao contexto que ele está inserido. Mister se faz também apontar para a necessidade de que os docente dos curso de formação inicial de professores tenham a real convicção do quê é quais a que se propõe um curso de licenciatura. Importante também que haja uma melhor comunicação entre professor e aluno como forma de o professor conhecer suas dificuldades buscar meios de promover alternativas que busquem melhorar o rendimento acadêmico do estudante.

A maioria dos entrevistados $(66 \%)$ poderia ter permanecido no curso, caso recebessem uma bolsa de pesquisa extensão ou ensino, de quatrocentos reais por mês, por exemplo. Certamente esse valor amenizaria problemas financeiros desse aluno que evadiu e poderia até ter evitado essa evasão, já que, conforme amplamente estudado por Tinto (1975, p. 100), “o status socioeconômico da família do aluno também são considerados no processo multidimensional que resulta em evasão". Miranda e colaboradores (2020) obtiveram resultados semelhantes em pesquisa no curso de Licenciatura em Física no IFRN - campus João Câmara.

Como percebemos, a participação em projetos como Pibic, Pibid ou de extensão podem constituir-se em estratégias para o combate da evasão escolar. Porém, esta pesquisa observou que 40\% dos entrevistados não participaram de nenhum desses programas. Os demais até participaram de projetos de pesquisa (19\%), extensão (13\%) ou Pibid (28\%), mas os mesmos foram descontinuados, por algum motivo. 
Apesar de boa parte dos alunos terem participado de algum projeto e mesmo assim decidirem evadir,

Devemos destacar que a oferta de bolsas por si só não vai acabar com a evasão estudantil, mas sim deve fazer parte de um conjunto sincronizado de ações envolvendo os demais estudante, assim como o corpo docente e de técnicos da instituição, de forma que o estudante se integre, se sinta pertencente a ela e tome a decisão de permanecer na mesma até sua efetiva diplomação.

No que diz respeito ao momento em que o estudante toma a decisão de sair do curso de Licenciatura em Química do IFMA - Monte Castelo, a pesar de em muitas turmas a saída ocorrer no primeiro ano, observa-se que alunos evadem a qualquer momento e por fatores diversos, como já anotados neste trabalho. Segundo Silva e Bregalda (2018, p. 115), quando a evasão ocorre no início do curso está relacionada a fatores pessoais, que podem estar associados a escolha do curso, dificuldades em se adaptar a imposições de professores assim como seus métodos de ensino, estranhamento em relação a diferença entre o curso superior e o ensino médio. Todavia, quando a evasão ocorre do sexto período para o final do curso pode estar relacionado a indecisão referente ao curso, juntamente com incertezas sobre a profissão escolhida que envolvem o mercado de trabalho.

Dessa forma, percebemos que a evasão estudantil está condicionada a vários aspectos, dentre eles um bom entendimento entre professor e aluno, saber lidar com a diferença entre a faculdade e o ensino médio, além da persistência do próprio aluno em superar as possíveis dificuldade encontradas durante o curso. Além disso, dentro dessa sucessão de múltiplos fatores, é imprescindível que as instituições de ensino superior se ocupem em levantá-los e analisá-los no sentido de compreender, prevenir, combater e, quiçá, reverter o fenômeno da evasão estudantil que tanto assola a qualidade da educação.

Nessa caminhada, toda a equipe de gestores e demais profissionais da instituição devem agir de forma a combater nessa guerra contra a evasão escolar. No entanto, um desses profissionais, pela própria natureza do cargo, é imprescindível nesse combate, o coordenador de curso. Sem dúvidas esse profissional é o gestor mais próximo do aluno, devendo ser o principal elo entre o estudante e o professor, assim como entre o estudante e os demais profissionais da instituição, inclusive os das equipes multidisciplinares (pedagogos, psicólogos, assistentes sociais, nutricionistas, médicos, dentistas, dentre outros). Pois, como destaca Vincent Tinto (1975, p. 111), "a interação institucional com o aluno faz parte do processo multidimensional do abandono, mesmo que essas questões sejam consideradas em conjunto".

Em face do exposto, como alertam Dore e Luscher (2011, p. 4), a evasão está relacionada a várias situações diversas que incluem repetência do aluno, a saída permanente da instituição e do sistema de ensino, assim como abandono da escola e um possível retorno. Assim, é possível compreender que o fenômeno evasão é um problema de extrema complexidade e que deve ser analisado com cautela para que possamos preveni-lo e combate-lo.

\section{Considerações Finais}

Percebemos que a maioria dos estudantes abandona o curso antes de seu término, por razões financeiras, mudança de município, distância, filhos/família, emprego/trabalho, dentre outros fatores. Dessa forma, para diminuir o índice de evasão estudantil seria interessante além de novos métodos de ensino, que a instituição desenvolva ações que estimulem os alunos a concluírem o curso, como programas de orientação a estudantes e maior suporte do corpo docente ao aluno.

Outra forma de estímulo à conclusão do curso, seria o aumento na oferta de bolsas, como as de iniciação cientifica, tecnológica ou à docência, por exemplo, como forma de resolver problemas financeiros. Também é imprescindível que, urgentemente, a instituição busque meios de ofertar vagas para ingresso nos dois semestres do ano, pois com uma única entrada, muito estudantes se veem obrigados a diminuir o número de disciplinas cursadas, o que, naturalmente, atrasa ou, em muitos casos, até paralisa seu curso.

Dessa forma, sugere-se que a instituição de ensino - gestores, equipes de apoio e corpo docente - deva buscar conhecer e analisar o problema da evasão estudantil, buscando compreender as principais causas desse fenômeno, dando mais apoio ao 
aluno dentro e fora de sala de aula, principalmente aos ingressantes, já que o primeiro ano de curso é decisivo para a tomada de decisão de permanecer ou evadir.

Por fim, recomenda-se que a pesquisa seja continuada, para melhor compreensão do fenômeno da evasão estudantil na formação inicial de professores no IFMA, inclusive com a inclusão de novos parâmetros - como a influência da pandemia de Corona vírus, por exemplo -, assim como de outros cursos e/ou áreas e/ou campi.

\section{Agradecimentos}

Os autores agradecem ao Instituto Federal de Educação, Ciência e Tecnologia do Maranhão (IFMA) e à Fundação de Amparo à Pesquisa e ao Desenvolvimento Científico e Tecnológico do Maranhão (Fapema) pelo apoio e pelo financiamento da pesquisa.

\section{Referências}

Abbad, G., Carvalho, R. S. \& Zerbini, T. (2006) Evasão em curso via internet: explorando variáveis explicativas. RAE Eletrônica. 5(2): 1-26. https://doi.org/10.1590/S1676-56482006000200008.

Adachi, A. A. C. T. (2009) Evasão e evadidos nos cursos de graduação da Universidade Federal de Minas Gerais. 214 p. Dissertação (Mestrado em Educação) - Faculdade de Educação, Universidade Federal de Minas Gerais. Belo Horizonte.

Almeida, J. B. \& Schimiguel, J. (2012) Avaliação sobre as causas da evasão escolar no ensino superior: estudo de caso no curso de licenciatura em física no Instituto Federal do Maranhão. Revista de Ensino de Ciências e Matemática, 2(2), 167-178. Doi: 10.26843/rencima.v2i2.64

Baggi, C. A. S. \& Lopes, D. A. (2011) Evasão e avaliação institucional no ensino superior: uma discussão bibliográfica. Avaliação, 16(2): $355-374$. http://www.scielo.br/pdf/aval/v16n2/a07v16n2

Biazus, C. A. (2004) Sistema de fatores que influenciam o aluno a evadir-se dos cursos de graduação na UFSM e na UFSC: um estudo no curso de ciências contábeis. 203 p. Tese (Doutorado em Engenharia de Produção) - Programa de Pós-Graduação em Engenharia de Produção, Universidade Federal de Santa Catarina - UFSC. Florianópolis, 2004. https://repositorio.ufsc.br/handle/123456789/87138

Brasil. (2000). Decreto n 3.462, de 17 de maio de 2000. Diário Oficial da União, Poder Executivo. http://www.planalto.gov.br/ccivil_03/decreto/d3462.htm

Brasil. (2008) Decreto No 7.566, de 23 de setembro de 1909. Diário Official de 26/09/1909. https://www2.camara.leg.br/legin/fed/decret/1900-1909/decreto7566-23-setembro-1909-525411-publicacaooriginal-1-pe.html.

Castro, A. K. Dos S. S. De \& Teixeira, M. A. P. (2017) Evasão universitária: modelos teóricos internacionais e o panorama das pesquisas no Brasil. Psicologia Argumento, 32(1): 9-17. Doi: https://doi.org/10.7213/psicol..argum.32.s02.AO01.

Colombo, I. M. (2020). Escola de Aprendizes Artífices ou Escola de Aprendizes e Artífices? Educar em Revista, 36(1), 1-28. Doi: https://doi.org/10.1590/ 1044060.71886

Costa, A. L. da. (1991) Evasão dos cursos de graduação da UFRGS em 1985, 1986 e 1987. Porto Alegre: UFRGS.

Dore, R \& Luscher, A. Z. (2011) Permanência e evasão na educação técnica de nível médio em Minas Gerais. Caderno de Pesquisa, 41(144), 772-789. https://doi.org/10.1590/S0100-15742011000300007

Dore, R., Sales, P. E. N. \& Castro, T. L. de. (2014) Evasão nos cursos técnicos de nível médio da rede federal de educação profissional de Minas Gerais. In: Dore, R.; Araújo, A. C. De; Mendes, J. de S. (Orgs.). Evasão na educação: estudos, políticas e propostas de enfrentamento. Brasília, DF: Ed. do IFB: RIMEPES, p. $379-413$.

Fritsch, R. (2015) A problemática da evasão em cursos de graduação em uma universidade privada. In: REUNIÃO NACIONAL DA ANPEd, 37ª edição, 2015, Florianópolis. Anais... Florianópolis: UFSC. https://www.anped.org.br/sites/default/files/trabalho-gt11-3986.pdf

Fritsch, R., Rocha, C. S. D. \& Vitelli, R. F. (2015) A evasão nos cursos de graduação em uma instituição de ensino superior privada. Revista Educação em Questão, 52(8), 81-108. https://doi.org/10.21680/1981-1802.2015v52n38ID7963

Instituto nacional de estudos e pesquisas educacionais anísio TEIXEIRA - Inep. Diretoria de Estatísticas Educacionais (DEED). (2017) Metodologia de Cálculo dos Indicadores de Fluxo da Educação Superior. https://download.inep.gov.br/informacoes_estatisticas/indicadores_educacionais/2017/metodologia_indicadores_trajetoria_curso.pdf

Lima, F. B. G. (2014) A formação de professores nos institutos federais de educação, ciência e tecnologia: um estudo da concepção política. Natal: IFRN. http://memoria.ifrn.edu.br/1044/325

Lorenzini, Elisiane. (2017). Pesquisa de métodos mistos nas ciências da saúde. Revista Cuidarte,8(2), 1549-1560. Doi: https://doi.org/10.15649/cuidarte.v8i2.406

Manfredi, S. M. (2002) Educação profissional no Brasil. São Paulo: Cortez. 
MEC - Ministério da Educação e Cultura. (1997) "Diplomação, Retenção e Evasão nos cursos de Graduação em Instituições de Ensino Superior Públicas". Brasília. http://www.dominiopublico.gov.br/pesquisa/DetalheObraForm.do?select_action=\&co_obra=27010

Miranda, M. H. V.; Nascimento, F. de L. S.; Maciel, S. C.; Soares, E. S. (2020) Evasão no Ensino Superior: uma análise do Curso de Licenciatura em Física do IFRN-Campus João Câmara (2009-2019). Research, Society and Development, 9(1), 1-21. Doi: 10.33448/rsd-v9i1.1757.

Moraes, G. H. et. al. Plataforma Nilo Peçanha: guia de referência metodológica. Brasília: Editora Evobiz, 2018. https://drive.google.com/file/d/1WLWTxdjNej448_VMVGsbC-wLMiT7r-9d/view

Nunes, R. C. (2013) Panorama Geral da Evasão e Retenção no Ensino Superior no Brasil (IFES). In: XXVII Encontro Nacional de Pró-Reitores de Graduação, Painel... Recife: FORGRAD. https://arquivos.info.ufrn.br/arquivos/201723623308a84006474291af3e089d2/2013_-_Painel_Forgrad_Agosto_-_Evasao.pdf..

ORGANISATION FOR ECONOMIC CO-OPERATION AND DEVELOPMENT. (2010) Education at a Glance: OECD Indicators. Paris: OECD. Doi: https://doi.org/10.1787/eag-2010-en

Parrino, M. C. (2009) La deserción y la retención de alunos: um viejo conflito que requiere pensar nuevas soluciones. GUAL, 2(1), 01-15. Doi: https://doi.org/10.5007/1983-4535.2009v2n1p01

Rangel, F. O; et al. (2019) Evasão ou mobilidade: conceito e realidade em uma licenciatura. Ciência e Educação, 25(1), 25-42. Doi: https://doi.org/10.1590/1516731320190010003

Ribeiro, J. L. L. S.; Morais, V. G. (2020) A possível relação entre o SISU e a evasão nos primeiros semestres dos cursos universitários. Revista Brasileira de Educação, 25(1), 1-17. Doi: https://doi.org/10.1590/S1413-24782020250040

Santos Junior, J. S., Real, G. C. M. (2017) A evasão na educação superior: o estado da arte das pesquisas no Brasil a partir de 1990. Avaliação, 22(2): 385-402. Santos, L. M. M. (2005) O papel da família e dos pares na escolha profissional. Psicologia em Estudo, 10(1), 57-66. https://www.scielo.br/j/pe/a/qBqcryfLqbvsnf7y6HkXNrv/?format=pdf\&lang=pt

Silva Filho, R. L. L. et al. (2007) A evasão no ensino superior brasileiro. Cadernos de Pesquisa, 37(132), 641-659. Doi: https://doi.org/10.1590/S010015742007000300007

Silva, B. E. N. da, \& Bregalda, M. M. (2018). Fatores associados à evasão de discentes de um curso de Terapia Ocupacional. Revista De Terapia Ocupacional Da Universidade De São Paulo, 29(2), 111-119. https://doi.org/10.11606/issn.2238-6149.v29i2p111-119

Tinto, V. (1975) Dropout from Higher Education: A Theoretical Synthesis of Recent Research. Review of Educational Research Winter, 45(1), 89-125. Doi: https://doi.org/10.3102\%2F00346543045001089

Tinto, V. (1997) Classrooms as Communities: Exploring the Education Character of Student Persistence. Journal of Higher Education, 68(6), 599-624. Doi: https://doi.org/10.2307/2959965

Tinto, Vincent. (1993) Leaving college: rethinking the causes and cures of student attrition. 2. ed. Chicago: The University of Chicago.

Vitelli, R. F., Fritsch, R. (2021). Evasão escolar na educação superior: de que indicador estamos falando?. Estudos Em Avaliação Educacional, 27(66), 908937. Doi: https://doi.org/10.18222/eae.v27i66.4009 